\title{
國际科学交流 苏联民族学的成就・
}

\author{
林䊒
}

（中央民战学院）

\section{$m$}

䒩苏民涘学学術会議每 5 年召开一次, 由苏 联科学院民族学研究所主持, 这次会議是粗1951 年会議以后召开的。会上总結了过去 5 尔來苏联 民族学工作的成果，样且討論了今后 5 年的研究 部划。

会議地点在列豈格勤。参加会譜的人数其約 350 人。此外, 还有 11 个國家派代婊參加了这次 会議。

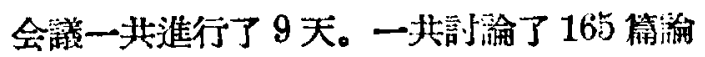
文. 8 个分組是按照研究問題的方面征区分的, 它們是:（1）文化处組，(2)民族史和早族地理 組，(3)苏联和人民民主國家条族的現代文化和 生活組，(4)資本主义和殖氐㴰国家各族的現代 文北和生活組，(5)原始社会史組，(b)人类学 組，(7)民間文学組，(8)博物官官工作組。从以 上組别的则分可以看出苏联民族奖研究閏題的废 泛。

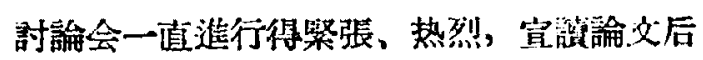

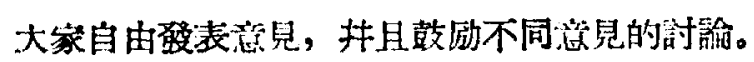
例如民族学老専家M. O. 柯㧹文提什了“结事民主

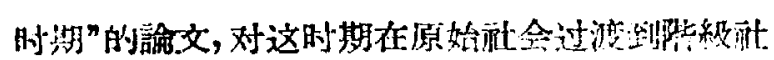
会的过程是否可以成立这一問题，大芜证不间，

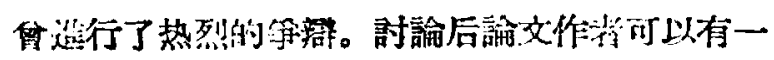

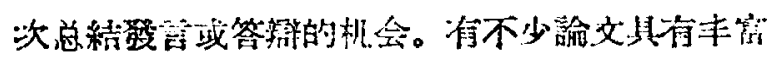

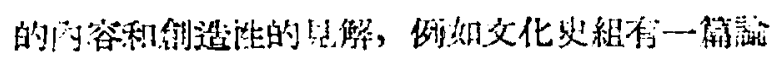

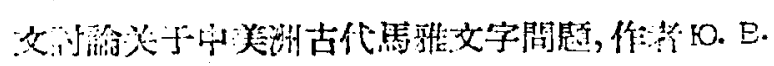

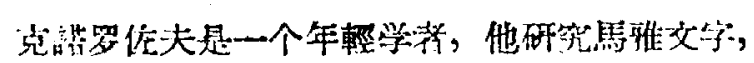

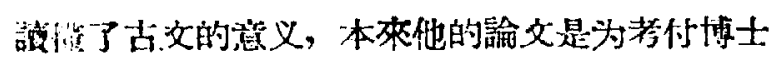
们撜出的, 因为諭文有㓣诰性的科学成就, 結果
投与作教博士学位。

在奈組会議上，苏联科学院民族学研究所所

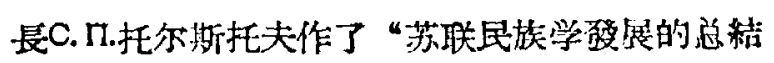
和前景”的主要报告, 引起了奎体渗加全議同志 的衙切注意。

嚜我們从这次民族学会議的学術間 踊討論


势。

远在十月草命以前，俄罗斯民族学已經積照

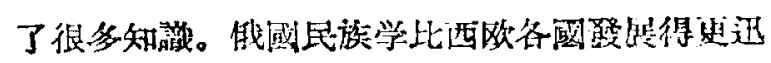

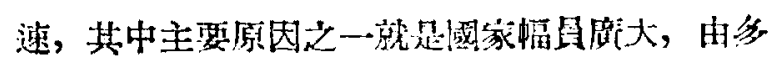



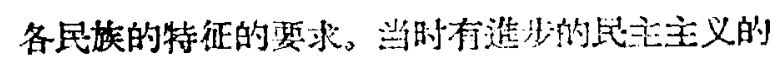
民族学，也有反动的崔心主义的谓㵀兴。

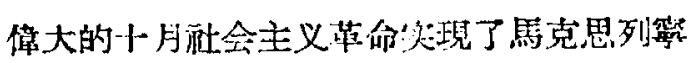
主义关于正族問題的理渝和政策，为放联各民族

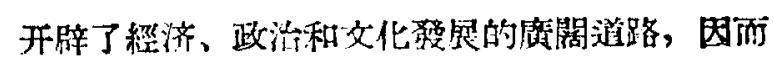

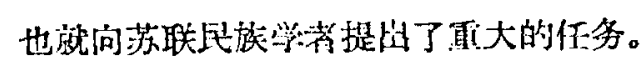

在衛國战争以前的等代里，苏联民族学渚由

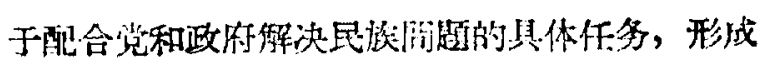
了独特的苏稚埃民族学学派。初斯在是族地抠的

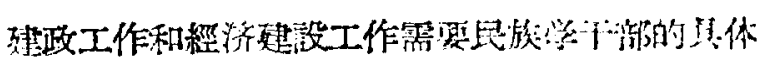
考察研究，特别在北方济后的地区实行地族政策

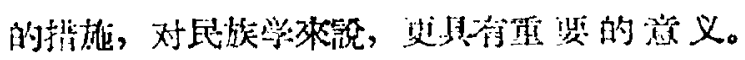

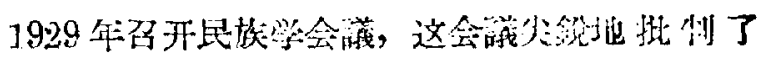

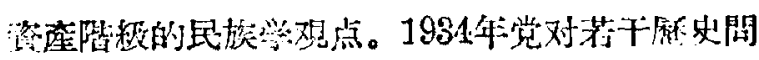

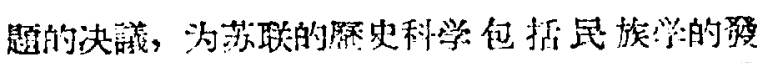

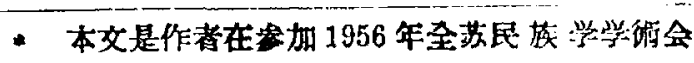
程后所赛报告的㨄要。 
层, 开鸽了一个新階段。莎联民族学的特点就是 微底的曆定主义，它把世界各民族作为人类全部 原程中的刢造歷电的主体来加以考察研究。这时 期民族学者对各民族的起源問題、原始社会史、 各民族的物管和精的文化問題，都進行具体的分

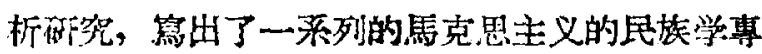
售。

1941年侄大的衛或战爭开始，苏联民族学的 科学研究工作很快稪到为或际服务, 例如批判种 族主义等。在战后年代里，更提出許多一般文化

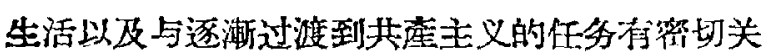
系的閣超，如研究民族团結問題（㩲大研究族源

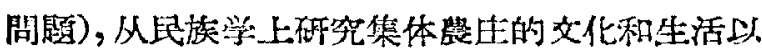


加了一項特殊的任务，就是研究各人民民主国家 的各民族，抹从思想上帮助他們。出于帝国主义 的反动陣营和社会主义的和本阵嘗之間的思想澺

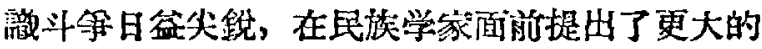
任务: 研究全计界沧国队的民族运动形式和民族 解放斗拿形式，批俩和揭露为帝國主义服务的反 动的民族学理編。因此，由于茄联國內和图外的 新形势，文促進了莎联民族学新的進一步的䈑 绿。

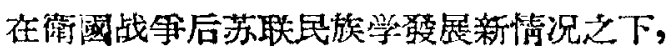

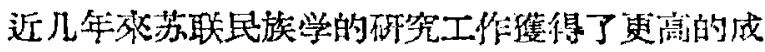
就。涀在只就几个主要方面简略地竾一談。

1. 关于現代各民族文化和生活的研究，比裤 是形会主义文化和生活的研究，是茄联昆族学最

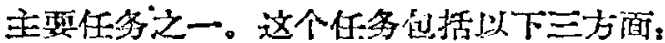


战拿以后，为了实际的目的，茄联民族学轉问研 垐誢代問影，那就是苏維埃时代的生活，首光是

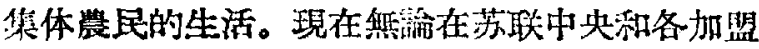
共和國以及自治省的研究机关中，这一研究的重 点任务，都占着顯著的地位。1948年到玩在已經 出現了一系列的專著和諭文，这次会議也拏重提 出这方面的問題。在C.П. 托尔斯托夫问志的总結

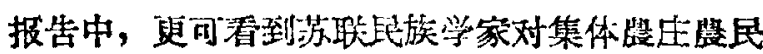
生活的研究，近來作出了主要的成結。在農民生 活的研究里，苏联民族学家已經能够賏徹原史分 析的原則，抹且也進一步更殿泛地吸收料材，加

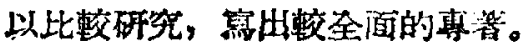

（乙）工人階般的生活一在苏联民族学家 面前还㨹学研究工人階极生活的任务，能够特别 注意到研究这一方面的問題，这也是苏联民族学 家的功䋶。关于革命前和革命后工人生活的研觉，

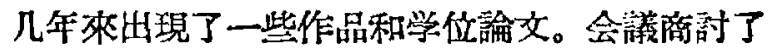
呼究工人生活的題目应該释常列入民族桨研究机 关的㸴究部划之中。


的苏联各族以及这些族的發展路綫䦗題一这地

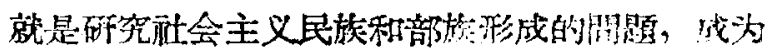

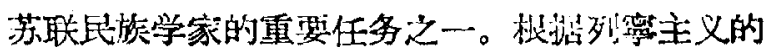

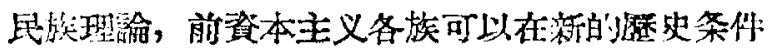

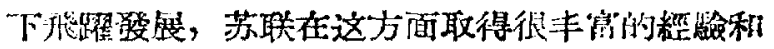
成䊓。会議号召加强这一方面的础究，因为它不 但具有实际上的意义，井且可以未薑馬克思列蜜 主义的民族理論。这一点对于研品中国的少数民

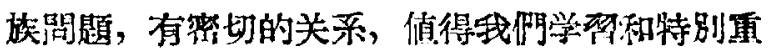
覞。

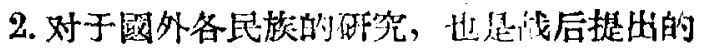
新的重大任务。近 5 年观作了不少工作，分以下 三方面。

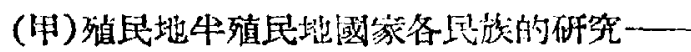
主要研究它們的現狀，特別注意在殖是地的条作

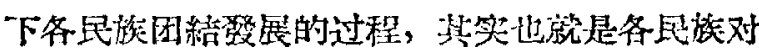
压迫溚、統治者斗爭的过䐎。有关非洲、澳洲、大

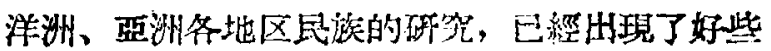

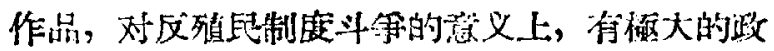
治雷要性。

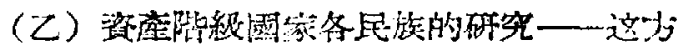

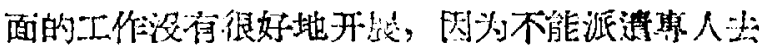
作实地調查, 但也存一些論文。会議行諭了这一 研究环節，趽为应当有必要的改進。

（韭）挌界人口的民族成分和各族的民族特 点的研究—这地是近年來中心阙题之一, 汸联 民族学家已經作了不少工作。相等多案本的一大

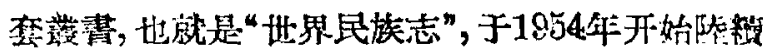
出版。这項巨大工程的目的是站程馬克思列究主 义的立場，对所有收集起來的民族学材料淮行一 次科学的称合工作。参与这一䅕䇣工作的包括多 数的苏联民族学家。

为配合“世界民族志”工作，縓制了惯界各族 地㖥本。这种地圖本也配合其他各种研究。从地圆 
上既可清清民分布，包括雜居地区，又可知道 人口接度; 从技術上看來，这雨力面的結合是苏 职民族学研究方法上的一个㓣造性的貢献。

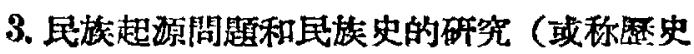
民族学）一一站去是現在仍旧是民族学最主要的 任学之一。十月革命后覚醒了的苏联各族人民不 能溯足于那些約乱的民族起源的神話傳說，他們

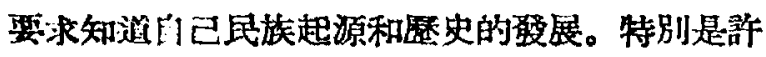
各民族都沿有自己文字記載的歷史傅統，民族学

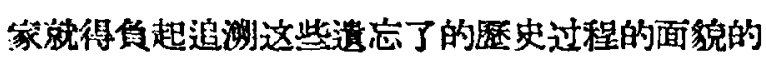
㨁任。

自三十年代起，是族起源問題减了苏联民族 学研究的一項中心工作。民族学者是以具体的民 族挐位。部落或部族，作为研究的基本对策，从研 究各个族的起源与形成問題逐漸了解到它的現代 生活。在这方面已經作了巨大的成綪, 不僅为糜 史民族学打下了基礎，而且实际上解决了許多民 族的起源和祭史形成的問題。

近年來族源研究的方法是組繶綜合考察榢， 洘察榢的䝿往往包括民族学、歴史学、考古学、 证高学和人类学等学科的工作者, 这一綜合研究

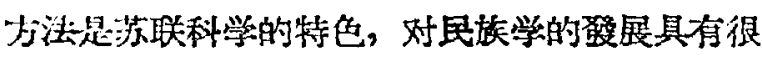

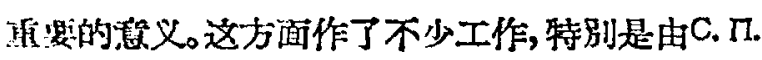
托尔斯托夫領运下的考察榢在花刺子模的研究成 綪更为恕著。这㳄会議狽論了俄罗斯民族的族源 開題，評划今后集中力量从事这一个重要的任务。

4. 原始触会史和氏族制度的研究，过去和現 在都是苏联民族学枓学做究重要任务之一。民族

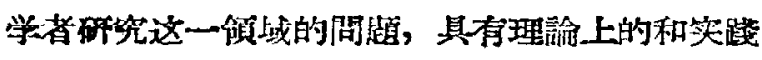
上的双面暗义。

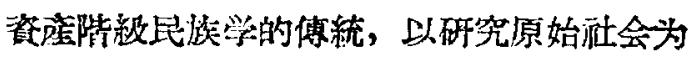
掫主要的任务，但把处在原始狪会的各旗視为

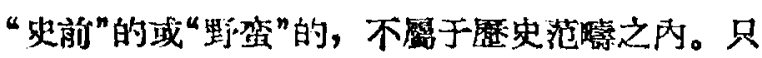
有在济会主义國家里，梏据馬克思列寧主义的科 当分析，矛起立原始㳩会史这一部門的研究，認 为原始社会即是人类歷史的开端。因此，原始社 会史这一科学研究領域，在理部上是和資涯階积 反动学說作斗争的前陗。苏联民族学家应用展泛 的新的具体材料去部明原史过程中的統一性，去 问朝原始社会一般性閣題，作了巨大的責献。他

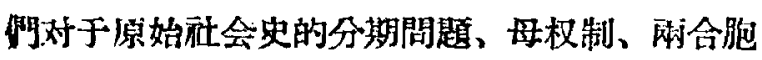
䛈組織，以及策事民主时期等問題，都淮行了較深

\section{入的分析。}

原始狪会史的研究在实践的意义上，上面已 橙提到在十月炗命前落后的民族，特别是極北方 和西伯利亞一些民族，在苏維埃制度的条件下， 如何过渡到社会主义的問題。在这里，民族学的 确究具有重大的政治意义。

近年來有关原始往会史的作品，出現了一采 列的尃著和諭文, 其中也包括考古学家的莎緛,

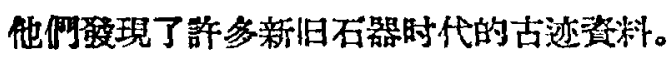

5. 民族学的研究还包括解多方面: 苏联民族 学家注空到各民族精和文化的研究，特别是民間 文学和宗教信们超余的問题。人类学在酒合民族



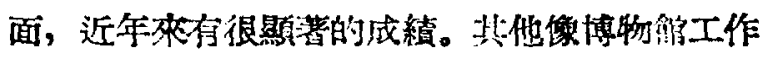

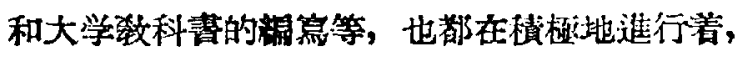
㚘得到了一定的成果。

从上上几个主要方面即可看出苏联民族学家 的姱力和成就。我國民族学者正在制訂向科学泎 軍的長远計划，很可以用来作渗。C. 几. 托尔 斯托夫所長在这次会蟻作总結报货时筑: “第二十” 次党代婊大会的榙增上，势出问人文科学方面各

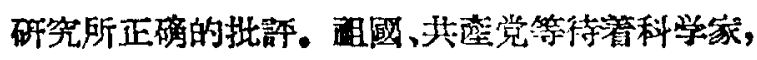
包括民雄学家在內, 坚决地改進工作, 把科学的 研究和共座主义的建設結合起桃，更進一步作出


对自己应作一切必要的答策。”这段絬㣜也同样可 以作为我們民族学工作的筬言。

\section{$\Xi$}

目前苏联民矤学和國际民族学的关系焦样，

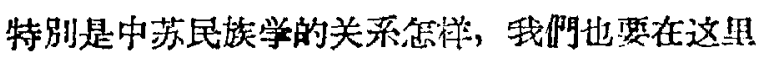

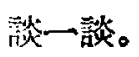

苏联民族学的研究在近年來开始注澺到陚际 間民族学工作的联系和合作，这次会議激請外何 代表加就是一个具体的例触。茫联科学管不但 要和人民民主國家的学者合作，也爭取和资体主

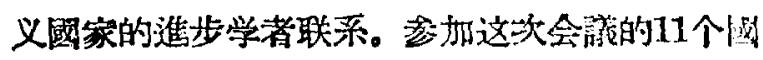
家的代表中，就有 3 个代表來当 3 个資本主义㖪 家。外國代婊也都在会議上作了报笘，進行了討 諭。外宾扭受到特別的优待, 开会时坐在主席时 上，宣亚諭文时不限定时腊，荕联和其他备感科 学傢对中国代表更是特別热情。 


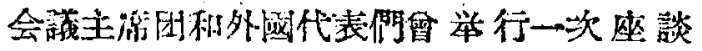
会, 討諭到际閣民族学的合作問題，如交流經驗、 交換作品和文物、互派湾和留学生以及亚相拫

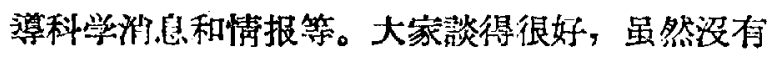
作出忛么具体的議䓩, 但为民族学的國际間合作 打下了一个良好的基礎。这炏座談会拆建議苏联 科学院民族学研究所出版的苏联民族学雜志, 开 辟一形作为行國民族学家交流科学情报的園地。

現在着重淡一下中茄雨國在民族学方面的关 弥。

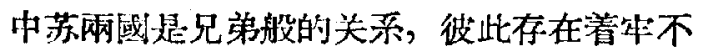
可破的友蚂，但在列族学方面这次会議还是初次

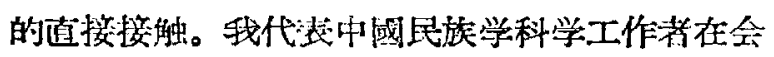
議上作了一个报告，题目是: “新中國在解决民放

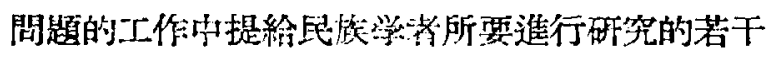
問题”。这箱报告队签仙括 3 个部分, 也就是解放 后理國是族学工作者所淮行的和正在進行的 3 个

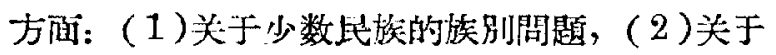
少数民族的社会性筫間題以及如何过渡到社会主 义社会的開題，(3) 关于少数民族的文化特点和 生活特点問题。

报告進行的情况很好, 大家非常感兴趣, 不


空，听众的反肤很好。䣄对报告提出問題和受表 意見的人很多。苏联民族学家对报告的意見旧納 起來分兩方面: 他們涩污报告的优点主要是:

1. 中國的民族登研究能够作到联䒺实际 醇言的人全部都提到中國民族学家能够做到理諭 和实䟠的結合。解放后的几年留中國的民族学考 作了不少工作，弡見了許多新的民族，对建設多 民族的大芜还是有碑献的。这些理諭和实践相絬

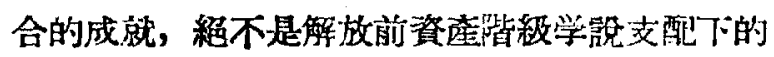
学者所能得到的，当然他們地不可能解决民族問

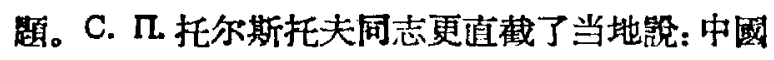
的施雄兴能为新社会服务。听众对这方面的反映 很热烈, 从上午报告后一直到晩問还有人热烈地 在談論渚中國的民族学筫正作到为政治服务。

2. 中国的民族学研究也有充分的理論基

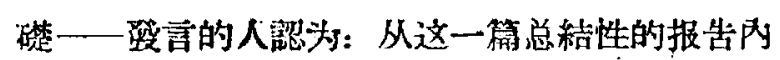

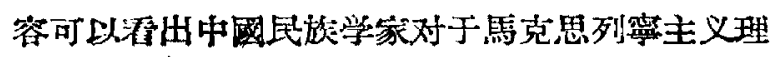

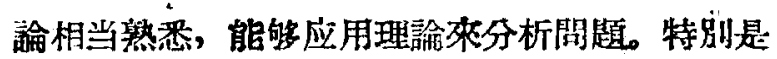
洌蜜格勒苏联各族人民民族学博物館館長H.M.染
斯罗夫同志提到报告中所引用的列案的話，有头

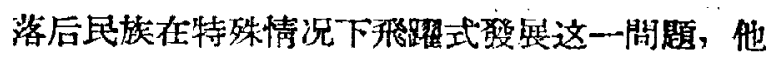
在二、三十年前即开始按照这一理諭切实地在河 伯利互工作而得到今日的效果, 目前中國民族学: 工作者再一次諭証了列管主义的理諭和政策。相 的同志还提到报告涉及的內容丰富抹能够在短时 間內作到全面性的叙求。他們对报告中諭逃少数

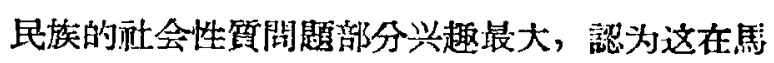
克思列政主义理論上有重大的突义。

3. 通过报告，苏联的民族学家認为中国民旗: 学对苏联民族学極有帮助，彼此需努合作。例如 中國的东北和西北地区的少数民族有汻多和苏职

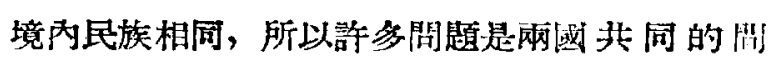
题, 需要互相协助, 能够組織联合考察榢更妒。他 們对中國西南地区的少数民族也有兴趣，例如等: 族的研究更有理論上的重要性。如果中國方面需 要与他們合作和协助的言萿, 他們随时随地都已䌌: 作好准备。苏联科学院民族学呼究所領導人 C.I.

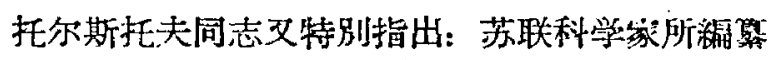
的亞洲民族志，如果汥有中國民族学家参加是不 能够完成任务的。最后他号召全㖄界的民族学老， 特別是中苏兩國的民族学者，要共同行动，以场 对民族学的登展做出貢献。

在会議上苏联民族学研究所副所長 $Л . \Pi$. .波搭 波夫领: 中國的这一篇諭交是这次学術討諭会中 最好的論文之一。

蚗点方面主要的提出兩点:

1. 对中國民族分布圖的意見一由中块民族 学院研究部繪制的中国是族分布圆存在着不少的 点, 經苏联專家們指出的有:（1）地㖥上滩有把 共同語采的各族用相近的啟色标示出來; (2)没 有把民族成分和人口篦度在地圖上同时顯示 H 來;（3 沒有雜居地区的标志，如內蒙古自治区 南部多系漢族，在分布圖上却看不仙来。

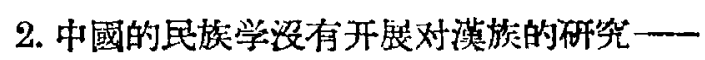
苏联民族学家希望中國民族学者合后也留从事漠 民族的研究工作，特别是怅業合作化运动大規模

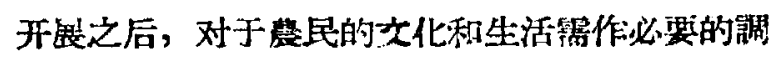
查研究。

总起來影，我們的这篇报告，初步总結了中

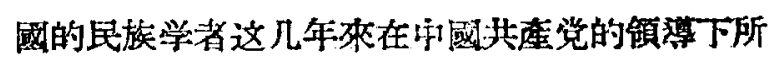
作的一些工作。从國际上对我們的部价可以看出， 
党所領蓪的工作方向是完全正确的。当然我倗的 工作还存在着䚺多缺点。苏联朋友們对我們的棓 价是在鼓励我們，我們自己应該看到自己的钢 点。

首先，限于时間，使我阿的这篇报告准备得 不够充分。其次报告本身是个工作报告的性質， 以后我們需要更多的叀門性的学街論文，因此就 急需开展梁入的研究工作。中央民族学院决定开 科学討論会抹派遗研究干部到民族地区作較長期 的調查工作，这便是鼓砢深入研究的方法。最 后，中國民族学研究的基礎不够，我們目前因限 于人力，只能集中力量对少数民族的問題進行研 究，但是不能忽略了漢族，同时也不应該忽略了 亞洲和世先各民族，我們要有相当度泛而堆厚的 基礎，才能談到更樑入地学術研究。

总之，我們的缺点虽然很多，但在党的領基 下，朝着正确的方问加倍努力，克服缺点，㧹 优点，学票苏联的先進經騟，結合國內的实际情 况，这样中國的民族学会有很廣閣的前途，12年 內赶上世界先淮水平也是可以达到的。

\section{四}

这次法加苏联民族学学術会議虽然只是一段 很短的时間, 但親自看到了很多新鮮的事物, 学 習了若干苏联科学的經驗，現在僅就个人一些主 要的体会和建議简單地提结，以供参考。

1. 首先体会到苏联民族学的科学研究有很大

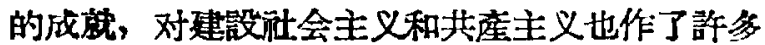
有价值的貢献，現在苏联的民族学家都信心百㥉 地和实事求是地努力争取苏維埃民族学更淮一步 的慰。

反覌國內情况，民族学作为一阴科学研究才

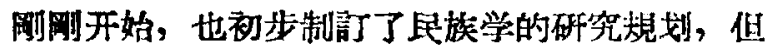
無論学得界或出版界对民族学还是生疏的, 作为 一門科学的名称还汥有統一起來, 不消铰在这学 科內的主要名詞更是淆乱不清。因此，我認为目 前民族学者主要任务之一，是研討和确定民族学 的科学詞量，苏联民族学家对我們也有同样的琶 求。

近年來很有一些同志間到民族学是什么? 它 特别和糜史学是什么样一种关系? 这次在苏联民 族学会議上也曾有一个年輕的同志詢問民族学的
定义是什么? 他种员怀疑不会有雨个相同的足 义。C.几.托尔斯托夫在紹束的会議上管复这个閣 題, 大意馀: “这次会議証明了民族学研究是一 个大的科学集体，我們知道作些什么工作，集体 也給我們䙺定了所要走的路綪，会議本身已經給 民族学是什么作出答案。因为空談定义不会有什

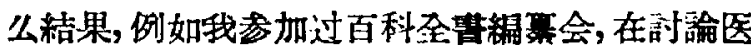
学的定义时用了网个小时，假如討諭尼族学的定 义恐怕时間还要花暂得更多。民族学是愿史科学 的一部分，与其他歴史科学的各部分沿有明顸的 分界，在民族学的研究上，有些情况非用歷史材料

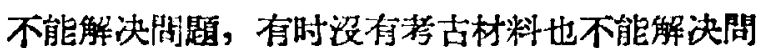
影，在史学研究上，有些重大問題滩有民族学的 材料也同样不能解决問題。二十年代即有人提問 民族学是什么，当时存在着各种不同的意見，不 管意見如何，我們不断地研究民族学而得到今天 的成果, 如果一定要空談民族学是什么，那么民 挨学就变成了䒺学。”我对C.几.托尔斯托夫同志的 这段話有很深的体会。和資暒階級学者把民族学 和歷史学对立起来的看法恰恰相反，馬克思列 主义的科学系統則浣民族学和程史学同虽于愿史 科学，所以它們之閏抹不是区别的治题洏是合作 的問题。当然民族学渚重淍查材料，暦史学清而 文塥紀錄，二者更应該案筑精合，不結合得好也 就不能作好工作。(1)

因此，我認为中國民族学的前途是密切地传 靠等它怎样来综成实际生活中所提出涞的具体任 务，現在即副要把这門科学范附划清，界碑樹

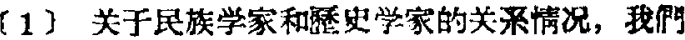
可引C.П.托尔激托夫同志的另一籍話: “荻䊒埃民族学研

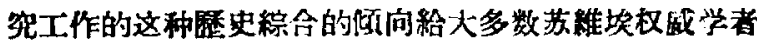

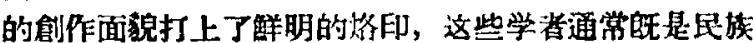

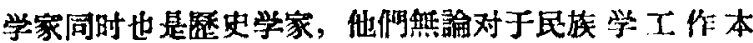
身，或是对于文献、檔案改考古资梅的研究工作都问样 有很高的修养。在許多情况下，不能瓴單地确定某个好



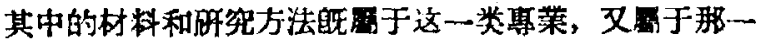

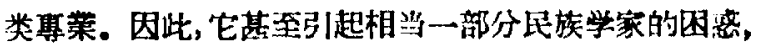

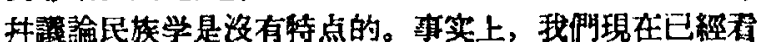
到苏倠埃民族学理諭的磁展情况, 它在今天已成曼为一 門面正的歷史科学，执在歷史知識的領域中取得了極其 更要的地位。此外，我附不能不指出它的另一方面: 在


学的材料，其中有很多人往往就袈成了道道地地的民族 学家。”（見“民族学的苏維埃学证”，原械苏联民族学雜 志，1947年第 4 期，王㬐讙) 
好，反而不能解决闍題。实际生活是丰富的、变 化的, 一旧科学能从这个丰富的变化的泉源出 它它的工作地会是活潑的、常新的。有了这种 認識，使我相信中國民族学一定会有無限的廣䦣 的前景。

2. 苏联民族学的特色之一，憱是綜合洘察榢 的办法，多少年乖科学家們用这种办法而獲得科 学上优异的成綪, 現在他們更大規模地發揮这办 法的作用。特别是有关民族起源問題和歷史民族 学的呼究，組成包括民族学家、歷史学家、考古 学家、人类学家和語言学家共同参加的綜合考察 榢，已往在花刺子模、波罗的海沿岸和吉尔吉斯 等地从事調查研究工作，这些紵合考察榢的秝驗 命人信服地証明了零解决族源問題和各族形成和 分布問題，非各种不同軎業的学者共同䋈力不 可. 这次会議号召蝩大組成綜合考察榢去研究俄 罗斯族的族源問題。諓們应当学習苏联民族学家 的这項先淮楥驗，派遗考察隊到少数民族地区進 行調查研究，尽量組䋐各洼关尃業的学者共同从 事于这一綜合性的科学研究工作。

3. 人类学是生物科学的一个部門, 但与人文

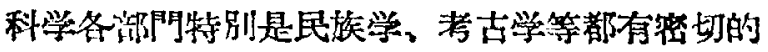
关系。在苏联科学院民族学研究所內，專設有人 类学部。民族学研究所所屬的列崇格勤民族学博 物館內也設有人类学悢。苏联人类学家無論在研 究人类起源和人种形成問題上，与研究民族起源、 分布、迁徙以及生活条件对各楼体筫的影响上， 都作了很多工作，对协助解决民族学上的問題， 地作了很大的貝献。

在國內人类学是需要加强的一个科学。因为 人类学在苏联和英、总資本主义國家有不同的意 义，近年來有些同志忽悓了人类学，以为人类学 是生物科学阴类和人文科学沿有什么关系似的。 其实有些民族重实上任括不同的种族成分或不同 体質类型成分，我們不能忽樭的，民族和种族在 意义上必须嚴格区別，但不能因为种族主义者惡 愬的徒曲科学事实，我們却把客覌上存在的东西 避洒不談, 实际上世只有从事科学的分析, 才能
揭露种族主义者的反动面目。

4. 苏联民族学在研究力法和技術上有許多㓣 造性的貢献。除了上面已提到的䋉合考察榢的办 法和歴史分析原則等之外，我在这里娎渚重镜明 民族分布圆粨繪法。这个䋧編法的基本原則，是 在地圖上配合地标示出來民族成分和各地区的人 口䎹度。这个原則虽然简單，但在編螕分布圖的


集奋关各个民族分布的相应的地理资料、人口㿠 計資料和記載資料，也包括理諭上的分类問題和 技石上的絧繪力法，这是一个相当复猚的科学研 究过程，但这种地圖的作用很大，因为各个民族 之間的相互关系及其分布原因在地圖，上越是更明 确地、更具体地表达法來，这个㘩圖在科学价值

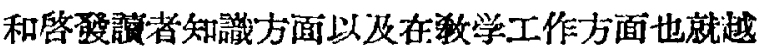
能取得更大的意义。苏联民族学家現在为了配合 世界民族志叢書和國內民族学的專著，已䅔繪制 成一系列的民族分布地圖本了。

我們地需要編繪民族分布圖，丰应准备訓䊂 这方面的專閒人中以便从事这項極有价值的工 作。

万. 在苏联，博物館工作非常發达，瓦族学博 物館工作是民族学的一个組成部分。这黑我用不 着說明博物館能为科学研究和数学工作服务, 论 还有对人民群众進行数育的直接意义。

在会議期中和会議之后，我参覌了許多博物 館，給子我極其深刻的印像，例如民族学博物㿥 陈列着世界各民族的文物，对殖民地民族光从他

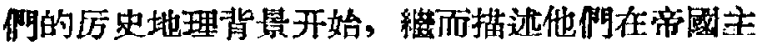
义压迫下的生活情况，最后是人民对压迫者的斗 爭，在这里表現了反殖民主义的情况以及指出了 民族解放的道路。又如苏联各族人民民族学博物 館的內容，主要是授揚各族的优主侮統，貫徽爱 國主义效育，井把各族糜史上到現在的文化和生 活的变化，特別是人民的刢浩性的活动，通通以 直覌的实物表現出來。

我國在科学工作的橆远筧划中，也应重旗博

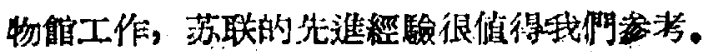

